\title{
The Thrill Is Gone: Burdensome Electronic Documentation Takes Its Toll on Physicians' Time and Attention
}

\author{
Mindy E. Flanagan, $P h D^{7}$, Laura G. Militello, $M A^{2}$, Nicholas A. Rattray, $P h D^{1,3}$, \\ Ann H. Cottingham, $\mathrm{MA}^{4}$, and Richard M. Frankel, $P h D^{1,4}$ \\ 'VA HSR\&D Center for Health Information and Communication, Roudebush VAMC, Indianapolis, IN, USA; ${ }^{2}$ Applied Decision Science, LLC, \\ Cincinnati, USA; ${ }^{3}$ Department of Anthropology, Indiana University-Purdue University Indianapolis, Indianapolis, USA; ${ }^{4}$ ndiana University School of \\ Medicine, Indianapolis, USA.
}

\begin{abstract}
KEY WORDS: electronic medical record; ambulatory care; physicianpatient relations; attitude to computers.

J Gen Intern Med 34(7):1096-7

DOI: $10.1007 / \mathrm{s} 11606-019-04898-8$

(C) Society of General Internal Medicine (This is a U.S. government work and not under copyright protection in the U.S.; foreign copyright protection may apply) 2019
\end{abstract}

\section{INTRODUCTION}

Exam room computing has become ubiquitous in outpatient clinic visits as electronic health record (EHR) documentation requirements for "meaningful use" are adopted. Despite its initial promise, EHRs have created several unanticipated consequences, not the least of which is that physicians' attention during patient visits being split between delivering care and completing EHR documentation tasks. Even with real-time documentation in the exam room, the majority of physicians spend additional time after hours completing EHR-related tasks. ${ }^{1}$ In a recent survey, physicians who reported inadequate time for documentation and "excessive" use of the EHR at home had higher rates of burnout. ${ }^{2}$

\section{METHODS}

We recruited a convenience sample of five Veterans Affairs physicians (four primary care physicians and one specialist) who agreed to participate in Cognitive Task Analysis (CTA) interviews. The interviews consisted of a task diagram, followed by a series of cognitive probes aimed at unpacking goals and specific strategies used to support documentation before, during, and after the patient encounter. ${ }^{3}$ CTA elicits a high-level description of a work process, followed by elaboration on key points. Interviews lasted approximately $1 \mathrm{~h}$ and were audio recorded. Data were organized as a series of case studies in order to compare overlaps and divergences related to (1) preparing for the visit; (2) enacting the visit, and (3) post visit documentation activities. Within each domain, goals, routines, divergences, and differences in participants' mental models were described.

Published online April 22, 2019

\section{RESULTS}

Study physicians consistently viewed exam room computing as competing with being patient-centered and did not find value in time spent on EHR-related tasks. One physician described that he wanted patients to feel that, "I'm paying attention and I'm not doing two things at once"; another stated that "documentation is a burden" and is "unreimbursed time." Strategies to manage the conflict between being patientcentered and completing documentation tasks created inefficiencies in workflow. In preparing for the visit, for example, several physicians made handwritten notes taken from the EHR to prompt them while seeing patients. As well, in lieu of using the EHR in the exam room, they made handwritten notes that had to be transcribed into the EHR or order entry system after the visit was completed.

Study physicians also worked on EHR tasks throughout the day. However, all required additional after-clinic hours to complete their documentation tasks (range $=30 \mathrm{~min}$ to $3 \mathrm{~h}$ per day). Some strategies for completing EHR documentation tasks efficiently were described: (1) pre-populating the EHR before seeing the patient; (2) using the copy and paste function from previous notes; (3) shortened patient visits; and (4) brief patient notes. Some physicians used in-room visit time to work on documentation; one physician described using the time patients prepared for their physical exam to do documentation. Physicians varied in the extent to which they created comprehensive notes for each visit. One physician described spending 2-3 h each evening documenting in the EHR to create clear and complete notes. By contrast, another physician described writing notes only to cover the "business of the day" limiting documentation to issues and treatments discussed during the visit. Physicians also described chronic stress from documentation burden and other computing requirements that negatively affected patient interactions and left them feeling guilty and losing resilience.

\section{DISCUSSION}

Although this group of physicians all asserted that the EHR competed for their attention and took time away from patients, they differed in how they adapted to these competing 
demands. These differences were largely attributable to their mental models of work. Some characterized cutting and pasting data from previous notes into the new note as a strategy for promoting continuity of care. Others acknowledged that this strategy requires a high level of vigilance to avoid introducing inaccuracies into the EHR. ${ }^{4}$ Also, the extent to which some exam room computing could be accomplished without negatively affecting patient relationships allowed some to complete EHR tasks during the patient visit while others refrained from it completely. More research in this area is needed to develop and implement an approach that effectively integrates computer use into the exam room without diminishing patientcentered care and physician resilience. ${ }^{5}$

Corresponding Author: Mindy E. Flanagan, PhD; VA HSR\&D Center for Health Information and Communication, Roudebush VAMC, 1481 W. 10th Street, Indianapolis, IN 46202, USA (e-mail: meflanag@iupui.edu).

Author Contributions Zamal Franks conducted two of the interviews but does not meet criteria for authorship.

Funding VA HRSD funded this work.

\section{Compliance with Ethical Standards:}

Conflict of Interest: The authors declare that they do not have a conflict of interest.

\section{REFERENCES}

1. Sinsky C ; Colligan $\mathbf{L}$; $\mathbf{L} \mathbf{i} \mathbf{L}$; et al. Allocation of physician time in ambulatory practice: a time and motion study in four specialties. Ann Intern Med. 2016; 165: 753-760

2. Olson K, Sinsky C, Rinne ST, et al. Cross-sectional survey of workplace stressors associated with physician burnout measured by the Mini- $Z$ and the Maslach Burnout Inventory. Stress Health. 2018. https://doi.org/10. $1002 /$ smi. 2849

3. Militello L, Hutton R. Applied cognitive task analysis (ACTA): a practitioner's toolkit for understanding cognitive task demands. Ergonomics. 1998;41(11):1618-1641.

4. Weis JM, Levy PC. Copy, Paste, and Cloned Notes in Electronic Health Records. Chest, 2014, 145(3); 632-638. https://doi.org/10.1378/chest. 13-0886.

5. Minal R Patel, Jennifer Vichich, Ian Lang, Jessica Lin, Kai Zheng; Developing an evidence base of best practices for integrating computerized systems into the exam room: a systematic review, J Am Med Inform Assoc, Volume 24, Issue e1, 2017, Pages e207-e215, https://doi.org/10.1093/ jamia/ocw121

Publisher's Note Springer Nature remains neutral with regard to jurisdictional claims in published maps and institutional affiliations. 